\title{
Do Fund Investors Know that Risk is Sometimes not
}

\section{Priced?}

\author{
Fabian Irek ${ }^{* \dagger}$ \\ University of Luxembourg \\ Thorsten Lehnert \\ University of Luxembourg \\ Second Version
}

January 2013

JEL Classifications: G11, G12, G23

*The present project is supported by the National Research Fund, Luxembourg.

†Corresponding Author: Luxembourg School of Finance, University of Luxembourg, 4 Rue Albert Borschette, L - 1246 Luxembourg, E-mail: fabian.irek@uni.lu, Tel: +352-4666445780, www.lsf.lu 


\begin{abstract}
Using the sentiment index of Baker and Wurgler (2006), we find that market risk is not a priced factor of expected fund returns when investor sentiment is positive. However, when sentiment is negative, the market risk premium becomes significant. We then analyze the performance of fund investors in the cross-section of market risk. We find that smart investors seem aware that funds' alphas do not vary with the state of sentiment, even though sentiment leads to patterns of funds' returns in excess of the market. Another key finding is that smart investors prefer the safest funds. The effects we document are economically significant: a trading strategy which is long in the positive cashflow portfolio and short in the negative cashflow portfolio yields an annualized alpha of 3.72 percent for the group of safest funds even after controlling for size, book-to-market and momentum.
\end{abstract}




\section{Introduction}

We find that risk is only a priced factor of expected equity mutual fund returns when investor sentiment is negative. However, when sentiment is positive, risk is not priced and the risk premium becomes insignificant. This striking relation holds for both total risk and market risk as measured by market beta while controlling for other well known risk factors. When we analyze the performance of fund investors in the cross-section, we find that investors buy equity funds which outperform and sell funds which underperform the average mutual fund the next month, but only for the group of safest funds.

One of our key findings is thus that "smart money" prefers funds which have the lowest exposure to the market as measured by market beta. While investor sentiment leads to patterns in the cross-section of funds' returns in excess of the market, smart investors seem aware that funds' alphas do not vary with the state of sentiment. Still, their trading activity leads to statistically and economically significant effects. For example, a trading strategy which is long in the positive cashflow portfolio and short in the negative cashflow portfolio yields an alpha of 31 bps per month or 3.72 percent per year for the safest funds. All these effects are short-lived and do not exist for longer holding periods than one month.

Our results contribute to two different strands of literature, the "smart money" effect and investor sentiment. It has long been hypothesized that fund investors are smart in the sense that they invest in funds which subsequently outperform and similarly disinvest from funds which subsequently underperform. This "smart money" effect is still under debate as literature has shown mixed evidence (Gruber (1996), Zheng (1999), Sapp and Tiwari (2004), or Keswani and Stolin (2008)). With mutual fund flows being nothing more than new investments into the fund market or a shift of existing investments, we are able to observe the behavior of many investors directly and hence gain some insights on investors' trading decisions and realized returns. We shed further light on this issue as little is known whether investors prefer safer or riskier funds.

We contribute to the literature by exploring the relation between expected returns and 
risk for fund investors. Another stream of the literature argues that investor sentiment affects the cross-section of stock returns. Baker and Wurgler (2006) use several market proxies to build a sentiment index and find that the extreme deciles of certain characteristic-sorted stock portfolios are related to their index. However, they do not show that sentiment is a priced risk factor. Unlike Baker and Wurgler (2006), we do not use the precise level of sentiment itself but whether the index is positive or negative. We do not show that sentiment is a priced risk factor but our result is far more subtle as the relation between expected returns and market risk is time-varying, and strongly depends on the state of sentiment. Our study is related to Yuan and Yu (2011) who use two different market indices to show that the meanvariance relation in equity markets only holds during negative sentiment periods. During positive sentiment periods, the relation is essentially flat and, as a result, investors are not compensated for risk. We hypothesize that smart fund investors should disinvest from the group of riskier funds if they do not receive a risk premium and if investors just care about outperforming the market and not alpha performance. Note that unlike Yuan and Yu (2011) we investigate the cross-section of assets which allows us to conduct a formal asset pricing test using the Generalized Method of Moments (GMM) of Hansen (1982). We offer an additional insight about market conditions as market and equity fund returns show significant autocorrelation during positive sentiment but none during negative sentiment periods.

The rest of the paper is organized as follows. In section II, we review the studies mentioned above in more detail and in section III we develop our main hypotheses. Section IV describes the data used, section V shows the empirical methods employed, and section VI shows our results. We conclude in section VII.

\section{Literature}

As mentioned in the introduction, the "smart money" effect is so far under dispute as the evidence is mixed. The first to address mutual fund investors' selection ability was 
Gruber (1996). He finds that money flows to funds, which subsequently on average outperform, even after controlling for risk. Thus, investors appear to be smart. Zheng (1999) finds that especially small funds entail a smart money effect in the U.S. from 1970 to 1993. Sapp and Tiwari (2004) control for Carhart's (1997) momentum and find that the "smart money" effect is completely explained by it, i.e. they find that returns earned by fund investors do not outperform the average mutual fund in the U.S. from 1970 to 2000. While chasing funds with high momentum loadings could still be considered smart, this is not the case for chasing past performance of funds. Since the authors find evidence for the latter but not for the former, they conclude that investors are not smart. Using monthly data for the U.S. and the U.K., Keswani and Stolin (2008) find again evidence for smart money. For the U.K., the authors find that both individual and institutional investors are smart regarding their buying but not their selling decisions. They then proceed to test U.S. data on the monthly and quarterly frequency and find that the findings of Sapp and Tiwari (2004) are due to their use of quarterly data and their weight on the pre-1991 period. Regardless of the momentum factor, Keswani and Stolin (2008) find that money seems to be "smart" in the U.S. after 1990.

While all these studies control for risk by using factor models, none of them analyzes expected returns in the cross-section. As mentioned in the introduction, recent empirical work tries to show that stocks which are hard to value or difficult to arbitrage experience a correction of their mispricing (Glushkov (2007)), which is prone to investor sentiment. Baker and Wurgler (2006) state that stocks which are highly subjective in terms of their valuations, will also be the riskiest and costliest to arbitrage. Thus, while the two effects differ, the same group of stocks will most probably be affected by both effects. In particular, small market capitalization stocks, young stocks, high volatility stocks, unprofitable stocks, non-dividend-paying stocks, extreme growth stocks, and distressed stocks are mostly related to lagged values of their index. Baker and Wurgler (2006) sort by just the aforementioned stock characteristics to construct portfolios long in one extreme decile and short in the op- 
posite decile. They then show that their sentiment index is a significant regressor even after controlling for other risk factors. However, by using only the extreme deciles' long-short portfolio and not the entire cross-section of stocks' alphas, they fail to show that sentiment is a priced risk factor. In other words, there seems to be another risk factor which even conditional factor models (Ferson and Schadt (1996)) do not fully account for, but only for a subgroup of stocks. In this paper, we follow a different path and do not try to include sentiment as an additional risk factor. One reason is that it seems unlikely that a fund's portfolio consists of only the aforementioned groups of stocks. Even if this were true for a part of the portfolio, the effects might be diversified away by the remaining stocks and sentiment might not be a priced risk factor. Still, the sentiment index of Baker and Wurgler (2006) is very helpful to allow for time variation. Yuan and $\mathrm{Yu}$ (2011) show that the sentiment index of Baker and Wurgler (2006) is even able to explain puzzles like the empirically not found mean-variance tradeoff of equity markets. They find that the mean-variance relation only holds during negative sentiment periods. Thus, there seems to be some evidence that sentiment influences the risk-return tradeoff. The authors argue that during periods of positive sentiment, more sentiment-driven traders are active in financial markets, which results in mispricing of assets like the absence of the mean-variance tradeoff. Additionally, those sentiment traders are reluctant to take short positions and can be expected to misestimate the variance of returns when sentiment is positive.

Stambaugh et al. (2012) shed further light on the issue that short-sale constraints exist due to institutional constraints. For example ${ }^{1}$, mutual funds are in general not allowed to short-sell securities. In the presence of short-sale constraints, overpricing should occur more often than underpricing. This happens because securities with high prices are not brought back to their fundamental value, as less optimistic investors will take no positions instead of short positions. Although positive sentiment periods lead to overpricing and lower returns, the existence of short-sale constraints might strengthen the mispricing market anomalies, for

\footnotetext{
${ }^{1}$ According to the authors, arbitrage risk, behavioral biases of traders, or trading costs are other possible constraints.
} 
which the authors find empirical evidence.

There is another study which links fund performance and the sentiment index. Using the sentiment index and fund portfolio holdings, Massa and Yadav (2012) build a sentiment contrarian behavior measure. Unlike them, we adapt the perspective of the investor to analyze performance.

\section{Hypotheses}

Many of the studies mentioned previously cite the seminal work of De Long et al. (1990). In their theoretical model, arbitrageurs may possibly not be willing to trade against market anomalies if noise traders create a specific market risk by their trading. Black (1986) introduces the concept of noise trading which is "trading on noise as if it were information" (p. 531). In other words, noise traders' demand for assets will be independent of their riskiness. If risky assets are bought regardlessly, they will not offer a risk premium when demand is high, leading to our first hypothesis: when sentiment is positive, riskier stock funds do not offer a risk premium. If this hypothesis cannot be rejected, it means that non-noise traders will not receive a premium which they normally demand. If this "smart money" is represented by arbitrageurs or other well informed traders, we would expect them to sell if the number of noise traders becomes too large, or to switch to assets with lower risk. Similar to Yuan and Yu (2011) we refer to times with high activity of noise traders as positive sentiment periods. If "smart money" accepts the lower returns of safer assets, we could expect to see outflows from the riskier group of funds into the safer group of funds when sentiment is positive and noise traders are active. Therefore, our second hypothesis is that "smart money" effects appear for sell-decisions of riskier funds and purchase-based decisions of safer funds when sentiment is positive. In short: if riskier funds underperform relative to less risky funds, it is not smart to hold riskier funds. This hypothesis can be motivated only if "smart money" looks at raw fund returns. While Sirri and Tufano (1998) advocate that 
fund investors who are mainly individual households look at unadjusted returns, the "smart money" literature focuses on risk-adjusted returns, too. We therefore interpret the second hypothesis as a means of household smartness. The alternative is that "smart money" does not look at raw returns but at risk-adjusted performance. However, once adjusting for risk factors, we do not necessarily expect any significant relation between alphas and sentiment.

Some authors regard fund flows as another source or proxy of investor sentiment. However, the evidence ${ }^{2}$ is mixed (Warther (1995), Goetzmann et al. (2000), Brown et al. (2005), Baker and Wurgler (2007), Ben-Rephael et al. (2011)). All these studies differ substantially from ours as they use either shorter samples of daily data or aggregate fund flows. However, in this study we deal with individual fund flows which are used to construct fund investors' gained returns. The next section presents the data used to test these hypotheses.

\section{Data}

\section{U.S. Mutual Funds}

Monthly mutual fund data is from Morningstar and free of survivorship bias. Since most studies on investor sentiment use U.S. domestic stocks only, we focus on funds investing into the same asset class and exclude industry focused funds ${ }^{3}$.

Morningstar introduced its classification system in 1996, but backfilled it for nearly all

\footnotetext{
${ }^{2}$ Goetzmann et al. (2000) use principal component analysis of daily U.S. mutual fund flows, classified according to eight major asset classes. Their first principal component has loadings which show a negative link between stock and bond fund flows. The authors interprete this as investor sentiment (see also Brown et al. (2005)). Ben-Rephael et al. (2011) investigate a proxy for monthly shifts between bond funds and equity funds. They find that this measure is negatively correlated with changes in the VIX and positively correlated with aggregate stock market excess returns. Warther (1995), on the other hand, analyzes whether returns of small-cap stocks are more sensitive to inflows than those of large-cap stock returns and if fund inflows and the closed-end fund discount are related. He finds no relation between aggregate fund flows and sentiment. Baker and Wurgler (2007) use Principal Component Analysis for major equity and bond classes. They show that the second principal component of flow changes has opposite loadings on speculative and safe funds flows.

${ }^{3}$ From the entire universe of U.S. open end mutual funds, we take the nine Morningstar equity fund categories Large-Cap Blend, Large-Cap Growth, Large-Cap Value, Mid-Cap Blend, Mid-Cap Growth, MidCap Value, Small-Cap Blend, Small-Cap Growth, and Small-Cap Value.
} 
funds in its database since then. Funds are categorized according to their average portfolio holdings over the past three years. For the main analysis, we use data at the portfolio level. Figure 1 shows the yearly total number of funds in our sample. Clearly, the mutual fund industry expanded enormously during the 1990s. The growth of the number of funds declined at the beginning of 2000 and eventually became negative in 2007 . The number of funds at the end of our sample period in 2010 is six times larger than at the mid point of our sample in 1987. Thus, the panel data set is unbalanced. The appendix shows how we filter the data and account for possible data errors. Our final sample ${ }^{4}$ has 3,800 different equity funds from 1965:08 to 2010:12. For months with no distributions, cash flows for fund $i$ are computed as $C F_{i, t}=T N A_{i, t}-T N A_{i, t-1}\left(1+r_{i, t}\right)$ and for months with distributions, Morningstar adds the distributions to cash flows. Otherwise, it would be assumed that investors reinvest all their capital gains or dividends. As common, we compute the standardized percentage flows as flow $_{i, t}=100 \times C F_{i, t} / T N A_{i, t-1}$.

As a measure of risk, we use fund return volatility, which is the standard deviation of the past twelve return observations of each fund.

\section{Investor Sentiment}

We use the yearly investor sentiment index ${ }^{5}$ of Baker and Wurgler (2006). Unlike survey based ${ }^{6}$ indices, the sentiment index uses market data or market related data only and tries to find the common signal in all those proxies. Using a composite index is advan-

\footnotetext{
${ }^{4}$ Due to data availability of monthly cashflows and TNAs, our analysis starts in 1991:02 and ends in 2010:12 when building the portfolios described above. For the 1968:08 to 2010:10 period, 264 months were in high sentiment states and 245 months in low sentiment states. For the 1991:02 to 2010:12 subperiod, 108 months were in high sentiment states and 131 in low states. Note that our sample ends in 2010:12 because this is the last month for which the sentiment index is available.

${ }^{5}$ We thank Jeffrey Wurgler for sharing his sentiment data. We obtained qualitatively similar results for both the monthly and yearly index, but present results for the yearly frequency because most authors use it.

${ }^{6}$ De Bondt (1993) uses the Bull-Bear spread of the American Association of Individual Investor (AAII) survey, and Lee et al. (2002) use the survey index of Investors Intelligence (II) as a proxy for institutional sentiment, though the interaction between the two is not very clear. Lee et al. (2002) correctly state that newsletters which are being evaluated for the index of Investors Intelligence (II) are subsequently read by retail investors. Verma and Soydemir (2009) find that retail and institutional investors take opposite positions in sentiment. Besides, survey data can be prone to the subjectivity of e.g. the editor who reads and interprets newsletters.
} 
tageous as one has not to test several single variables against each other. Besides, it is possible to filter out idiosyncratic noise and to find the common component behind all variables. The sentiment index (SENT) is the first principal component of six different variables which have been shown to measure investor sentiment, but with different timing. Variables which depend on investor demand might lead variables which depend on firm supply decisions. Variables which depend on investor behavior include the average of first-day returns on IPOs (Ritter (1991)), the closed-end fund discount (Lee et al. (1991)), NYSE share turnover (Baker and Stein (2004)), and the dividend premium, while the equity share in new issues (Baker and Wurgler (2000)) and the number of IPOs (Ritter (1991)) involve firm supply responses. To ensure that it is not the business cycle which drives results, Baker and Wurgler (2006) build an orthogonalized version ${ }^{7}$ of their sentiment index, denoted $\mathrm{SENT}^{\perp}$. All variables have the expected sign and expected timing ${ }^{8}$ except the closed-end fund discount which enters without a lag. Figure 1 shows the $\mathrm{SENT}^{\perp}$ index. Clearly, it coincides with anecdotal evidence of stock market sentiment. During the recent financial crisis, sentiment became negative and remained so from 2008:11 onwards. It is common to lag the sentiment index by one year as this allows to find patterns of mispricing corrections. Baker and Wurgler (2006) find that when $\operatorname{SENT}_{t-12}^{\perp}$ is positive, subsequent returns of small market capitalization stocks, young stocks, high volatility stocks, unprofitable stocks, nondividend-paying stocks, extreme growth stocks, and distressed stocks are relatively low and vice versa. We do not use the level of $\mathrm{SENT}_{t-12}^{\perp}$ but allow the equity market to have two states of sentiment. As in Yuan and Yu (2011), we define a month as being in a low or negative (high or positive) sentiment state if $\mathrm{SENT}_{t-12}^{\perp}<0$ (if $\mathrm{SENT}_{t-12}^{\perp}>0$ ). The advantage of distinguishing sentiment by this nonparametric approach of just two states is that results

\footnotetext{
${ }^{7}$ Each of the sentiment proxies is first regressed on six macroeconomic variables which are growth in industrial production, real growth in durable, nondurable, and services consumption, growth in employment, and a dummy for NBER recessions. The residuals are then used to build the first principal component $\left(\mathrm{SENT}^{\perp}\right)$.

${ }^{8}$ Note that the closed-end fund discount, which is the average net asset value of closed-end equity fund shares minus the market prices of their underlying portfolios, and the dividend premium, defined as the $\log$ difference of the average market-to-book ratios of dividend-paying and nonpaying stocks, are inversely related to sentiment.
} 
should not be driven by specific values of sentiment variables.

\section{Performance Measures}

Researchers are puzzled why people keep investing in mutual funds, given that the average fund is shown to earn an annual Jensen's alpha somewhere between zero or slightly below (Jensen (1967), Brown and Goetzmann (1995), Ferson and Schadt (1996), Carhart (1997)). However, traditional factor models fail to take the actual investment decisions into account. Hence, we use fund investors' flows as weights and compare different trading strategies and their resulting portfolios ${ }^{9}$ of funds as in Gruber (1996), Zheng (1999), Sapp and Tiwari (2004), or Keswani and Stolin (2008):

1. Equally weighted portfolio of all available funds.

2. Equally weighted portfolio of all available funds with positive flows

3. Equally weighted portfolio of all available funds with negative flows

4. Cashflow weighted portfolio of all available funds with positive flows

5. Cashflow weighted portfolio of all available funds with negative flows

For each portfolio, we calculate cross-sectional means as $\sum_{i=1}^{N} r_{i, t} w_{i, t-1}$ for each month where $w_{i, t-1}$ is the portfolio weight for fund $\mathrm{i}$ at the end of period $\mathrm{t}-1$, and $r_{i, t}$ is the return of fund $\mathrm{i}$ between periods t- 1 and $\mathrm{t}$. This formula is the main essence of the "smart money" literature as it measures the return of an investment over the next month ${ }^{10}$. Portfolio 1 is just the average performance of all available funds. The other portfolios are based on past newly invested money signals. In particular, portfolios 2 and 4 are based on positive flow weights, hence they measure the return of fund investors who have just invested into a fund

\footnotetext{
${ }^{9}$ Thoughout this paper, we follow the "portfolio regression approach" of Zheng (1999). Note that she also presents another approach where risk adjusted returns are not calculated at the portfolio level but the individual fund level and then aggregated. This "fund regression approach" can also be found in Gruber (1996) and Keswani and Stolin (2008), while the "portfolio regression approach" can be found in Sapp and Tiwari (2004), too.

${ }^{10}$ Note that we do not use the contemporaneous flows as weights because fund investors could observe the within month performance of funds.
} 
over the next period. Portfolios 3 and 5 are based on negative flow weights, and measure the return of funds which have been sold previously. For each portfolio, we use the resulting time series to compare different performance measures like the excess return over the market, $r_{p, t}-M K T_{t}$, where $M K T_{t}$ is the value-weight return on all NYSE, AMEX, and NASDAQ stocks. Besides this, we estimate the Fama-French three factor model together with the momentum factor of Carhart (1997). As in Stambaugh et al. (2012), we estimate:

$$
\begin{aligned}
r_{p, t}-r_{f, t}= & \alpha_{p}^{L} D_{t}^{L}+\alpha_{p}^{H} D_{t}^{H}+\beta_{p}^{1} M K T R F_{t}+\beta_{p}^{2} S M B_{t}+\beta_{p}^{3} H M L_{t} \\
& +\beta_{p}^{4} M O M_{t}+\varepsilon_{p, t}
\end{aligned}
$$

where following the usual convention the monthly excess return of portfolio p over the risk-free rate, i.e. the 1-month T-Bill return, is denoted by $r_{p, t}-r_{f, t}$, and the excess return on the market minus the risk-free rate is denoted by $M K T R F$. All fund returns are net of expenses. The average return on the three small minus the average return on the three big market capitalization portfolios is denoted by $S M B$ (Small Minus Big) and $H M L$ is the average return on two value minus the average return on the two growth portfolios as in Fama and French (1993). Carhart's $M O M$ is the average of the returns on two (big and small) high prior return portfolios minus the average of the returns on two low prior return portfolios where prior returns are measured from month $t-12$ to $t-2$ (Carhart (1997)).

We do not use three factors only because Sapp and Tiwari (2004) show that momentum explains the smart money effect in their quarterly data sample. Keswani and Stolin (2008) on the other hand find that this is not true for their monthly sample. We incorporate sentiment which consists of two possible states, i.e. either a positive or negative sentiment state, by using two dummy variables as intercepts. $D_{t}^{H}$ is a dummy variable which equals one in high sentiment periods and zero otherwise, while $D_{t}^{L}$ is one under low sentiment and zero otherwise. 
Throughout this paper, all standard errors are adjusted for heteroskedasticity and autocorrelation according to the method of Newey and West (1987) using four lags.

\section{Results}

\section{Autocorrelation of Returns and Summary Statistics}

Our hypotheses rely on changing states of sentiment. Table 1 panel A shows the independent variables of the factor models used in low and high sentiment states (1968:08 to 2010:12). Each parameter has its t-value below in parentheses. Besides, we test for the equality of the parameters in low and high sentiment periods and present the t-value in brackets in the last row. Excess market returns are essentially zero when sentiment is high but at 76 basis points (bps) per month when sentiment is low. Although the test of equality t-value is at 1.52, the difference is not statistically significant. Panel B shows means for the sample periods where flow data is available (1991:02 to 2010:12). When sentiment is low, the market excess return is of 138 bps per month but negative and insignificant when sentiment is high. This difference is statistically different at 3.08, also. Interestingly, fund equity excess returns show a similar relation as shown in panel C. We pick up this point below. Some of the other series show evidence for time-variation, too, but we believe stock market returns to be the most important benchmark for mutual fund returns and want to focus on them first. Besides, the other variables are significant either in panel A but not B or vice versa. The summary statistics allow us to have a first look at hypothesis one. The second column presents the one month autocorrelation of stock market excess returns in low and high sentiment periods, denoted by $\rho(1)$. Interestingly, the autocorrelation is at zero when sentiment is low but significant at 0.13 when sentiment is high, although the difference is not significant with a t-value of 1.13. If arbitrageurs do not drive prices back to fundamentals, market returns should be less independent over time when sentiment is high, for which we find evidence. The second column of panels $\mathrm{C}$ and D shows that similar 
results are obtained for the excess returns of equity funds. For our entire sample period the one month autocorrelation of fund excess returns is at 0.16 and significant when sentiment is high while at only 0.07 and insignificant when sentiment is low. The difference between both means is not statistically different either. Hence, this can only be regarded as a quick test of market efficiency to motivate our study. Still, to our best knowledge this finding in conjunction with investor sentiment has not been documented before.

\section{Expected Returns of Portfolio Sorts}

To check for pattern in the cross-section of funds' risks and returns, we rank funds each month into five quintiles according to their return standard deviation over the prior twelve months. The first row of Panel A in Table 2 shows time series averages of cross-sectional means of equity fund returns for each quintile. Funds with lowest risk of quintile 1 yield an average return of 76 bps per month, while the group of the riskiest funds earns 93 bps. The sixth column shows that this low economical difference of 17 bps is not significantly different from zero in statistical terms. Panel $\mathrm{C}$ shows averages of the risk variable. Quintile 5 has an average return standard deviation which is more than twice that of the group of funds with lowest risk. Hence, there is considerable cross-sectional difference of risk but not of returns. Thus, there is some evidence that riskier funds do not pay higher expected returns during our entire sample period (1968:08 to 2010:12).

Next, we allow the equity market to have two sentiment states as indicated by the first column of the table. The second row of panel A shows average returns in low sentiment periods. There is now some evidence that higher risk is compensated with higher expected returns. Safest funds earn about 89 bps per month on average, while the riskiest funds earn about 148 bps. This difference of 58 bps is statistically significant, too. The third row shows return averages in high sentiment periods. The risk-return tradeoff is nearly flat. While quintiles 1 to 3 earn statistically significant returns, quintiles 4 and 5 have returns which are not significantly different from zero. The second and third row of panel C show average risk 
in low and high sentiment periods. Risk as measured by historical standard deviation seems not to be higher when sentiment is high as none of the t-statistics of the last row denoted by high-low are significant.

For robustness, we repeat the analysis for the subsample which is from 1991:02 to 2010:12 and used for the portfolios below ${ }^{11}$. Panels B and D show that the same results are obtained. The safer a fund, the lower its expected return when sentiment is low. Safest funds of quintile 1 earn 128 bps while the riskiest funds of quintile 5 earn 200 basis points in average per month. When sentiment is high, this pattern disappears. When averaging across both sentiment states, the risk-return tradeoff does not hold cross-sectionally (see first row).

In summary, there is strong evidence for hypothesis one: When sentiment is high, riskier funds do not return more than safer funds. The effects are of high economical significance, and robust to different sample periods. One might argue that this finding seems natural given that the market return in excess of the riskfree rate is of only -39 bps and insignificant when sentiment is high but in that case one would rather expect a reverse relation in the cross-section, i.e. that the riskiest funds earn less than the safest funds. We find however that the risk-expected return relation is essentially flat when sentiment is high, not reversed.

\section{Testing the Market Risk Premium}

Since there exist different notions of risk than our employed total risk, we sort equity funds each month into quintiles by their systematic risk to ensure that our results so far were not driven by idiosyncratic risk. For each fund $i$ at time $t$, we estimate the four factor model

$$
r_{i, t}-r_{f, t}=\alpha_{i}+\beta_{i}^{1} M K T R F_{t}+\beta_{i}^{2} S M B_{t}+\beta_{i}^{3} H M L_{t}+\beta_{i}^{4} M O M_{t}+\varepsilon_{i, t}
$$

based on the three Fama-French factors and Carhart's momentum variable using the 36 month prior values of each variable. We then use the estimated $\hat{\beta}_{i}^{1}$ for our sorts and obtain

\footnotetext{
${ }^{11} \mathrm{We}$ used returns in excess of the risk-free rate, too. Our results remained unchanged.
} 
five time series of excess returns. Panels A and B of table 3 show that sorting by market and size beta yields results which are most similar to our standard deviation sorts. Sorting by other factor loadings as shown in panels $\mathrm{A}$ and $\mathrm{B}$ of table 4 yields different results. We want to perform a real asset pricing test now to see which risk premia are priced in low and high sentiment periods. Recall that a factor pricing model has an expected return-beta expression where the betas are from a multivariate regression

$$
\mathbf{r}_{t}=\mathbf{B} \mathbf{F}_{t}+\mathbf{e}_{t}
$$

and the expected returns are linear in the betas

$$
E\left(\mathbf{r}_{t}\right)=\mathbf{B} \boldsymbol{\lambda}_{F}
$$

$\mathbf{r}_{t}$ is our $5 \times 1$ vector of excess returns or test assets, $\mathbf{F}_{t}$ is a $4 \times 1$ vector of factors, $\mathbf{B}$ a $5 \times 4$ matrix of betas, and $\boldsymbol{\lambda}_{F}$ is the vector of factor risk premia $\left(\lambda^{M K T R F} \lambda^{S M B} \lambda^{H M L} \lambda^{M o m}\right)^{\prime}$. As factors we simply use the three Fama French and a momentum factor as before ${ }^{12}$. A straightforward approach to test whether market risk is priced (i.e. whether $\lambda^{M K T R F} \neq 0$ ) would be to use Fama and MacBeth (1973) regressions. The problem with this procedure is that estimated regressors (e.g. the $\hat{\beta}_{i}^{1}$ ) are used in cross-sectional regressions of equation (4), thus leading to error-in-variables bias. We avoid this problem by estimating the risk premia of $\boldsymbol{\lambda}_{F}$ using the Generalized Method of Moments (GMM) of Hansen (1982). Let $\mathbf{b}$ be the vector of unknown parameters $\boldsymbol{\lambda}_{F}$, and B. Let $E_{T}$ be the sample mean $E_{T}=(1 / T) \sum_{t=1}^{T}$ and the sample moments be $\mathbf{g}_{t}(\mathbf{b})=E_{T}\left[\mathbf{u}_{t}(b)\right]$, where $\boldsymbol{u}_{t}(\mathbf{b})$ are the pricing errors. The GMM estimator of $\boldsymbol{b}$ then minimizes the weighted sum of squared pricing errors $\mathbf{g}_{t}(\mathbf{b})^{\prime} \mathbf{W} \mathbf{g}_{t}(\mathbf{b})$ where $\mathrm{W}$ is a weighting matrix. In particular, we first use the identity matrix to start with $W=I$ and then use the optimal weighting matrix $W=\hat{S}^{-1}$ where $S$ is the spectral density matrix of $u_{t}, S=\sum_{j=-\infty}^{\infty} E\left[u_{t} u_{t-j}^{\prime}\right]$ where $u_{t}$ has been evaluated at the consistent estimates

\footnotetext{
${ }^{12}$ We tried different specifications e.g. with only MKTRF as single factor, or where we used deciles instead of quintiles. Our results remained unchanged. Tables are available upon request.
} 
of $\boldsymbol{b}$ from the first optimization. Intuitively, this means that assets which moment conditions have a higher variance will get smaller weights and thus the second stage estimator is efficient (Cochrane (1996)). Our moment conditions then read

$$
\mathbf{g}_{t}(\mathbf{b})=\left[\begin{array}{c}
E_{T}\left(\mathbf{r}_{t}-\mathbf{B} \mathbf{F}_{t}\right) \\
E_{T}\left(\mathbf{r}_{t}-\mathbf{B} \mathbf{F}_{t}\right) \mathbf{F}_{t} \\
E_{T}\left(\mathbf{r}_{t}-\mathbf{B} \boldsymbol{\lambda}_{F}\right)
\end{array}\right]
$$

We present results in table 5. The left column of Panel A shows that the market risk premium $\lambda^{M K T R F}$ is of 42 bps per month or 5.04 percent per year for our full sample for the four factor model. We then split our sample into positive and negative sentiment periods and repeat the GMM estimation. When sentiment is negative, $\lambda^{M K T R F}$ is larger, at 76 bps per month. Strikingly, the estimate is at only 11 bps per month but insignificant when sentiment is positive. Panel B shows the same results are obtained for the subperiod from 1991:02 to 2010:12 which is used for the "smart money" analysis below. The market risk premium is negative at -39 bps per month but insignificant when sentiment is negative. Hence, taken together with the results of our quintile sorts earlier, there is some evidence that market risk is not priced during high sentiment periods. The sorts from above indicate that the size effect could drive our results, too. We repeat the analysis by sorting funds into quintiles according to the $\hat{\beta}_{i}^{2}, \hat{\beta}_{i}^{3}, \hat{\beta}_{i}^{4}$ obtained earlier and report the respective market risk premia, e.g. when sorting by $\hat{\beta}_{i}^{3}$ we report $\lambda^{H M L}$. The table shows that the risk premium $\lambda^{S M B}$ is only priced during low sentiment periods while the risk premia $\lambda^{H M L}$ and $\lambda^{M o m}$ are only priced during high sentiment periods. Note that this holds for the subperiod in panel B, too. The J-test of overidentifying restrictions does not reject any of our models on all conventional levels of significance. 


\section{Cashflow Weighted Portfolio Results}

In this section, we analyze the performance of equity fund investors, and whether it is related to the state of sentiment. Panel D in table 1 shows that the average monthly flow to equity funds is of $80 \mathrm{bps}$ in low and $63 \mathrm{bps}$ in high sentiment periods. This difference is not statistically significant. We proceed by using the flow portfolios.

\section{Excess Equity Fund Returns}

We present results for the flow weighted portfolio or trading strategies conditioned on sentiment. Table 6 panel A shows portfolio returns in excess of the market return when sentiment is positive or high, and panel B shows results when sentiment is negative or low. Each parameter has its t-value below in parentheses. We test for equality of the average excess return of the average fund and the excess return of the flow weighted portfolios and present the t-test statistic in brackets. Besides, we test if the excess returns are equal in low and high sentiment periods and present this t-test statistic in angle brackets.

Panel A shows that when sentiment is high, all equity funds earn zero returns in excess of the market, while the group of the riskiest funds even underperform it by -17 bps per month, though this is not significantly different from zero.

Turning to equally weighted portfolios with positive flows below, we find that safest funds outperform the market by 16 bps per month although the parameter itself is not significant. In one out of five cases, the t-test statistic in brackets is significant pointing that the purchase based portfolio outperforms the average mutual fund. This relation is monotonically decreasing in market risk, but not statistically different (the t-value is at -1.14). The flow weighted portfolios show only weak evidence of any "smart money" effects because none of the parameters is significant. On the other hand, it shows no clear underperformance either.

As mentioned above, we do not hypothesize any special investor skill when market risk is priced during low sentiment periods. Results in the upper part of table 6 panel 
B seem not surprising given that they are similar to those in panel B of table 2 except that they are in excess of the market: Safer funds (quintiles 1, 2 and 3) underperform the market when sentiment is low while the riskiest funds outperform the market, though the latter finding is not statistically significant. Still, the difference between the riskiest and the safest funds is significant at 40 bps per month. Here, we find more evidence for the "smart money" effect. As indicated by the significant t-values in brackets, we find that all the equally weighted portfolios with positive (negative) flows outperform (underperform) the average mutual fund. For example, investors sell the riskiest funds which subsequently underperform by -31 bps per month or 3.72 percent per year. For the flow weighted portfolio with negative flows we get similar results, but somehow weaker. Interestingly, the group of safest funds is the only quintile which has a significantly different excess return in low and high sentiment periods as indicated by its t-value at 2.26 or 1.99 in angle brackets. Thus, there is some evidence that fund investors are "smart" for both buy and sell-based portfolios which is mostly concentrated on least risky funds. Interestingly, this happens independently of the state of sentiment, the excess returns earned however are significantly different from each other. Note that although investors are able to beat the average mutual fund, they still earn zero or negative excess returns when sentiment is low. The effects we observe are strongest for the sell-based portfolios 3 and 5 of safest funds. This speaks against hypothesis two since there are no pattern that investors shift their money from riskiest into least risky funds. Our key finding is thus that "smart money" is active in the group of least risky funds independent of the state of sentiment.

\section{Risk-adjusted Fund Returns}

We turn to results of alpha performance. The table 7 shows results of equation (1). Each parameter has its t-value below in parentheses. Similar as before, we test for equality of the average alpha of the average fund and the alpha of the flow weighted portfolios and present the t-test statistic in brackets. We test if the alphas are equal in low and high 
sentiment periods and present the t-test statistic in angle brackets. None of the t-tests in angle brackets is significant. The equity fund alphas thus do not show the same pattern of the excess fund returns as they are adjusted for market risk now, and for the sake of brevity we report alphas for the full sample only. As before, the safest funds of quintile 1 have the strongest effects. Purchase-based portfolio 4 outperforms the average mutual fund while sell-based portfolios 3 and 5 underperform it. Thus, although sentiment leads to different return pattern depending on being low or high they disappear once controlling for other risk factors. Still, there are cross-sectional differences. Table 8 shows that a trading strategy long the flow-weighted purchase-based portfolio and short the sell-based portfolio has a monthly alpha of 31 bps or annualized 3.72 percent. The question arises whether this is economically significant or not. Sapp and Tiwari (2004) find a statistically significant alpha of 7.1 bps per month for their positive flow portfolio and interpret its as evidence for "smart money". In that respect, our alphas are much higher. In unreported results, we form portfolios on SMB, HML and MOM loadings, as well as on combinations of them but do not find any pattern.

\section{Characteristics of MKTRF Funds}

As mentioned earlier, Zheng (1999) finds that "smart money" effects are strongest for smaller funds. Since mutual funds have decreasing returns to scale (Berk and Green (2004)), smaller funds might employ trading strategies which lead to low market betas. As a consequence, our results could be explained by the possible correlation of market beta and fund size. We perform sorts on MKTRF betas and report the average TNA of each quintile in

the first row of table 9. Clearly, our results seem not to be driven by the fund size effect of Zheng (1999). The low beta funds of quintile 1 have an average monthly TNA which is 256 Mio $\$$ U.S. larger than that of quintile 5.

Since some of our portfolios use fund flows as weights it could be important to check the flows for patterns. This seems important since the smart money effects we document for the group of safest funds could be caused by very small flows. The second row shows that 
this is not the case. Of all quintiles, the first one has the largest average flow.

The third row shows the average turnover ${ }^{13}$ of funds. Low beta funds of quintile 1 trade 39 percent less than high beta funds of quintile 5, which is a substantial difference. Interestingly, turnover is monotonically increasing with market beta. If low beta funds trade much less, their expenses could be lower, too. However, this is not the case. The market beta-expense ratio $^{14}$ relation is U-shaped as can be seen in row four. Although quintile 1 funds charge 5 bps less than the ones of quintile 5, the difference is of low economical importance.

One might object that using single sorts by market betas does not allow to detect relations of market beta and other beta loadings. The next three rows show that low MKTRF beta funds have average SMB, HML and MOM betas which belong to the mid-quintiles of our earlier beta sorts (see panel D of table 3, and panels $\mathrm{C}$ and D of table 4). Still, low market beta funds could have time-varying beta loadings on SMB, HML or MOM. Similar to the holdings-based style consistency measure (HSV) of Brown et al. (2012), we calculate a style volatility measure (RSV) based on fund returns, not portfolio holdings. For each fund, we compute the standard deviation of the quintile rank using the last 36 months of data of the SMB, HML and MOM loadings. Thus, if a fund switches e.g. its exposure from large- to small-cap stocks over time as detected by its time-varying SMB beta of equation (2), its rank changes from quintile 5 to quintile 1 , and the standard deviation of the rank will be larger than that of a fund which stays in large-cap stocks. The RSV measure is simply defined as the average of all three rank standard deviations, $R S V=\left(\sigma^{\text {caprank }}+\sigma^{\text {btmrank }}+\sigma^{\text {momrank }}\right) / 3$. The last row of shows that the safest and riskiest funds have the highest values for RSV, but the difference among both quintiles seems not economically significant given that the difference in RSV to all other quintiles is larger.

\footnotetext{
${ }^{13}$ The turnover ratio measures the trading activities of a fund, calculated as the lesser of purchases or sales divided by average monthly TNA.

${ }^{14}$ The expense ratio is the percentage of fund assets deducted for operating expenses like management fees, administrative fees $12 \mathrm{~b}-1$ fees and operating costs. Not included are the fund's brokerage costs or any load charges.
} 


\section{Summary}

In summary, we find strong evidence for hypotheses one and three but not for hypothesis two. When sentiment is high, riskier funds do not offer a risk premium, but there are no signs that investors shift their money from the riskiest to the safest funds. We detect "smart money" effects for both the purchase-based and sell-based portfolios of safest funds independent of the state of sentiment and these effects are economically strong. When we control for other risk factors there are no alpha differences between low and high sentiment periods, but the group of safest funds still shows significant alphas. Thus, it seems that "smart money" is not misled by cross-sectional differences in fund returns caused by different sentiment states. Instead, "smart money" seems to be interested in obtaining the highest Sharpe ratios possible. Subtracting the average riskfree rate which is of 45 bps for the full sample (28 bps for the flow subsample of panel B) from each quintile return in table 2 and dividing it by the respective standard deviation below shows that the group of safest funds has at all times the highest of all Sharpe ratios. Our results are in line with Grinblatt et al. (2011) who show that investors with higher IQs are more likely to hold mutual funds, have lower-beta portfolios than lower-IQ participants and earn higher Sharpe ratios.

\section{Further Robustness Checks}

Instead of ranking funds each month, we ranked them at the beginning of each year, also. This is important because the monthly rebalancing is a contrarian strategy ${ }^{15}$ that exploits reversal, which in turn can cause higher performance of the equal-weighted portfolio (Plyakha et al. (2012)). Our results however remained unchanged.

Our sorts rely on historical beta loadings or historical standard deviation. We model each fund return as a GARCH $(1,1)$ process and use the monthly volatility in our quintile ranks. Since many investors might be concerned if their fund does not track its benchmark, we compute the tracking error ${ }^{16}$ of each fund and use it in our sorts, too. Neither the use of

\footnotetext{
${ }^{15}$ We are thankful for this comment.

${ }^{16}$ The tracking error variable is the twelve month rolling standard deviation of the difference between a
} 
the $\operatorname{GARCH}(1,1)$ nor the use of tracking error did change our results.

For robustness, we tried different specifications for equations (1) where the betas were allowed to have two states, too (Ferson and Schadt (1996)). Ferson et al. (2008) show that suppressing time-variation in betas causes the conditional alpha to be biased. Using simulations, Jha et al. (2009) argue that their conditional investment opportunity set measure ${ }^{17}$ which employs time-variation in alpha only is less biased than the conditional alpha measure of Ferson and Schadt (1996). Our results remained qualitatively unchanged when trying all these models.

We estimate equation (1) with the traded liquidity factor of Pastor and Stambaugh (2003). Since most of our alphas change slightly, e.g. often by only one basis point, we report results without the liquidity factor.

The flow portfolios measure the return or alpha earned over the subsequent month. We analyze longer holding periods up to 36 months but do not find any pattern for the MKTRF betas sorted funds. Hence, it seems that the "smart money" effects we find are short-lived. All of our robustness checks are available as tables upon request.

fund's return and its benchmark. Although a fund might choose a benchmark which can easily be beaten, or in reality track another benchmark, the tracking error might still matter as it is published and advertised by funds in order to attract new investors' money.

${ }^{17}$ Note that the Jha et al. (2009) conditional alpha performance measure has been applied with the sentiment index in levels as an instrument in Berger and Turtle (2012). 


\section{Conclusion}

In this study, we find that market risk of U.S. mutual funds is only priced when sentiment is low. When sentiment is high, the risk premium is insignificant. We then investigate the cross-sectional pattern in U.S. fund investors' performance conditioned on high and low sentiment. We find evidence for "smart money" effects for purchase and sell-based portfolios of funds with lowest riskiness independent of the state of sentiment, although the market excess returns are different. These effects exist for both purchase- and sell-based portfolios. Although investors buy funds which perform better than the average mutual fund when sentiment is low, they still earn negative returns in excess of the market. Once controlling for other risk factors, the alpha differences between low and high sentiment periods disappear. "Smart money" effects are still observable for the group of safest funds, and the four-factor alpha is economically large at 3.72 percent per year.

Interestingly, we find that results are strongest for the extreme quintile of the safest funds. This is in line with Grinblatt et al. (2011) who show that differences in investors' IQ, and not only wealth or risk aversion, lead investors to hold different portfolios. If investors' IQs and "smartness" are correlated, we would expect "smart" investors to hold portfolios or mutual funds which offer the best risk-expected return tradeoff or Sharpe ratios. We find that "smart money" follows the funds with the highest Sharpe ratios and seems to understand that risk-adjusted performance measures are robust to the cross-sectional pattern in fund returns caused by different sentiment states. 


\section{References}

Baker, M.,Stein,J.,2004. Market liquidity as a sentiment indicator. Journal of Financial Markets 7,271-299.

Baker, M.,Wurgler,J.,2000. The equity share in new issues and aggregate stock returns. Journal of Finance 55,2219-2257.

Baker, M.,Wurgler,J.,2006. Investor sentiment and the cross-section of stock returns. Journal of Finance 61,1645-1680

Baker, M.,Wurgler,J.,2007. Investor sentiment in the stock market. Journal of Economic Perspectives 21,129-151.

Ben-Rephael, A., Kandel S.,Wohl, A, 2011. Measuring Investor Sentiment with Mutual Fund Flows. Journal of Financial Economics, forthcoming.

Berger,D., and Turtle, H.J., 2012. Cross-sectional performance and investor sentiment in a multiple risk factor model. Journal of Banking \& Finance, 36, 1107-1121.

Berk, J. and R. Green, 2004. Mutual fund flows and performance in rational markets. Journal of Political Economy, 112, 1269-1295.

Black, F, 1986. Noise. Journal of Finance 41, 529-543.

Brown K.C.,Harlow W.V.,Zhang H., 2012. Investment Style Volatility and Mutual Fund Performance. Working paper.

Brown, S. J., Goetzmann, W. N., 1995, Performance persistence. Journal of Finance, 50, 679-698.

Brown, G.W.,Cliff,M.T.,2004. Investor sentiment and the near-term stock market. Journal of Empirical Finance 11,1-27.

Brown, S.J., Goetzmann, W.N., Hiraki, T., Shiraishi, N., Watanabe, M, 2005. Investor Sentiment in Japanese and U.S. Daily Mutual Fund Flows. Working paper. 
Carhart, M. M.,1997. On Persistence in Mutual Fund Performance. Journal of Finance, 52, $57-82$.

Chen,J.,Hong H., Huang M.,Kubik J.D., 2004. Does Fund Size Erode Mutual Fund Performance? The Role of Liquidity and Organization. American Economic Review,94,1276-1302.

Chevalier, J., Ellison,G., 1997. Risk Taking by Mutual Funds as a Response to Incentives. Journal of Political Economy 105, 1167-200.

Cochrane,J.H., 1996. A Cross-Sectional Test of an Investment-Based Asset Pricing Model. Journal of Political Economy, 104, 572-621.

De Bondt, W. P. M., 1993. Betting on trends: Intuitive forecasts of financial risk and return. International Journal of Forecasting, 9, 355-371.

De Long,B.J.,Shleifer,A.,Summers,L.H.,Waldmann,R.,1990. Noise trader risk in financial markets. Journal of Political Economics 98,703-738.

Elton, E. J., Gruber, M. J., Blake, C. R.,2001. A First Look at the Accuracy of the CRSP Mutual Fund Database and a Comparison of the CRSP and Morningstar Mutual Fund Databases. Journal of Finance, 56 , 2415-2430.

Elton, E. J., Gruber, M. J., Blake, C. R., Krasny, Y., Ozelge, S. O., 2010. The effect of holdings data frequency on conclusions about mutual fund behavior. Journal of Banking \& Finance, 34, 912-922.

Fama, E.F.,French, K.R., 1993. Common Risk Factors in the Returns on Stocks and Bonds. Journal of Financial Economics, 33, 3-56.

Fama, E., MacBeth J., 1973. Risk, return, and equilibrium: Empirical tests. Journal of Political Economy, 81, 607-636.

Ferson, W. E., Schadt R. W., 1996. Measuring fund strategy and performance in changing economic conditions. Journal of Finance, 51, 425-461. 
Ferson, W.E., Sarkissian, S., Simin, T.,2008. Asset Pricing Models with Conditional Betas and Alphas: The Effects of Data Snooping and Spurious Regression. Journal of Financial and Quantitative Analysis, 43, 331-353.

Glushkov, D., 2007. Sentiment Beta. Unpublished paper.

Goetzmann, W. N., Massa, M, Rouwenhorst. K. G, 2000. Behavioral Factors in Mutual Fund Flows. Yale School of Management Working Paper.

Grinblatt, M., Keloharju, M., Linnainmaa, J., 2011. IQ and Stock Market Participation. The Journal of Finance, 66, 2121-2164.

Gruber, M. J.,1996. Another puzzle: The growth in actively managed mutual funds. Journal of Finance 51, 783-810.

Hansen, L.P., 1982. Large Sample Properties of Generalized Method of Moments Estimators. Econometrica, 50, 1029-54.

Ippolito, R., 1992. Consumer reaction to measures of poor quality: evidence from the mutual fund industry. Journal of Law and Economics 35, 45-70.

Jensen, M.C., 1967. The Performance of Mutual Funds in the Period 1945-1964. Journal of Finance,23,389-416.

Jensen, M. C., 1969. Risk, the pricing of capital assets, and evaluation of investment portfolios. Journal of Business 42, 167-247.

Jha, R., Korkie, B., Turtle, H.J., 2009. Measuring performance in a dynamic world: conditional mean-variance fundamentals? Journal of Banking \& Finance 33, 1851-1859.

Keswani, A., Stolin, D., 2008. Which money is smart? Mutual fund buys and sells of individual and institutional investors. Journal of Finance, 63, 85-118.

Lee, C.,Shleifer,A.,Thaler,R.H.,1991. Investor sentiment and the closed-end fund puzzle. Journal of Finance 46,75-109. 
Lee, W. Y., Jiang, C. X., Indro, D. C., 2002. Stock market volatility, excess returns, and the role of investor sentiment. Journal of Banking \& Finance, 26, 2277-2299

Massa, M.,and Yadav, V.,2012. Do Mutual Funds Play Sentiment? Working paper.

Newey, W., West, K., 1987. A simple positive semi-definite, heteroskedasticity and autocorrelation consistent covariance matrix. Econometrica, 55, 703-708.

Pastor, L., Stambaugh, R.F., 2003. Liquidity Risk and Expected Stock Returns. Journal of Political Economy, 111, 642-685.

Plyakha, Y., Uppal, R., Vilkov, G., 2012. Why Does an Equal-Weighted Portfolio Outperform Value- and Price-Weighted Portfolios? Working paper.

Ritter, J.,1991. The long-run performance of initial public offerings. Journal of Finance 46,327.

Sapp, T., Tiwari, A., 2004. Does stock return momentum explain the "smart money" effect? Journal of Finance, 59, 2605-2622.

Stambaugh, R.F., Yu,J., Yuan, Y., 2012. The Short of It: Investor Sentiment and Anomalies. Journal of Financial Economics, 104,288-302.

Sirri, E., Tufano, P., 1998. Costly search and mutual fund flows. Journal of Finance 53, $1589-1622$.

Warther, V. 1995. Aggregate mutual fund flows and security returns. Journal of Financial Economics 39, 209235.

Yuan, Y., J. Yu, 2011. Investor sentiment and the mean-variance relation. Journal of Financial Economics, 100,367-381.

Zheng, L., 1999. Is money smart? A study of mutual fund investors' fund selection ability. Journal of Finance, 54, 901-933. 


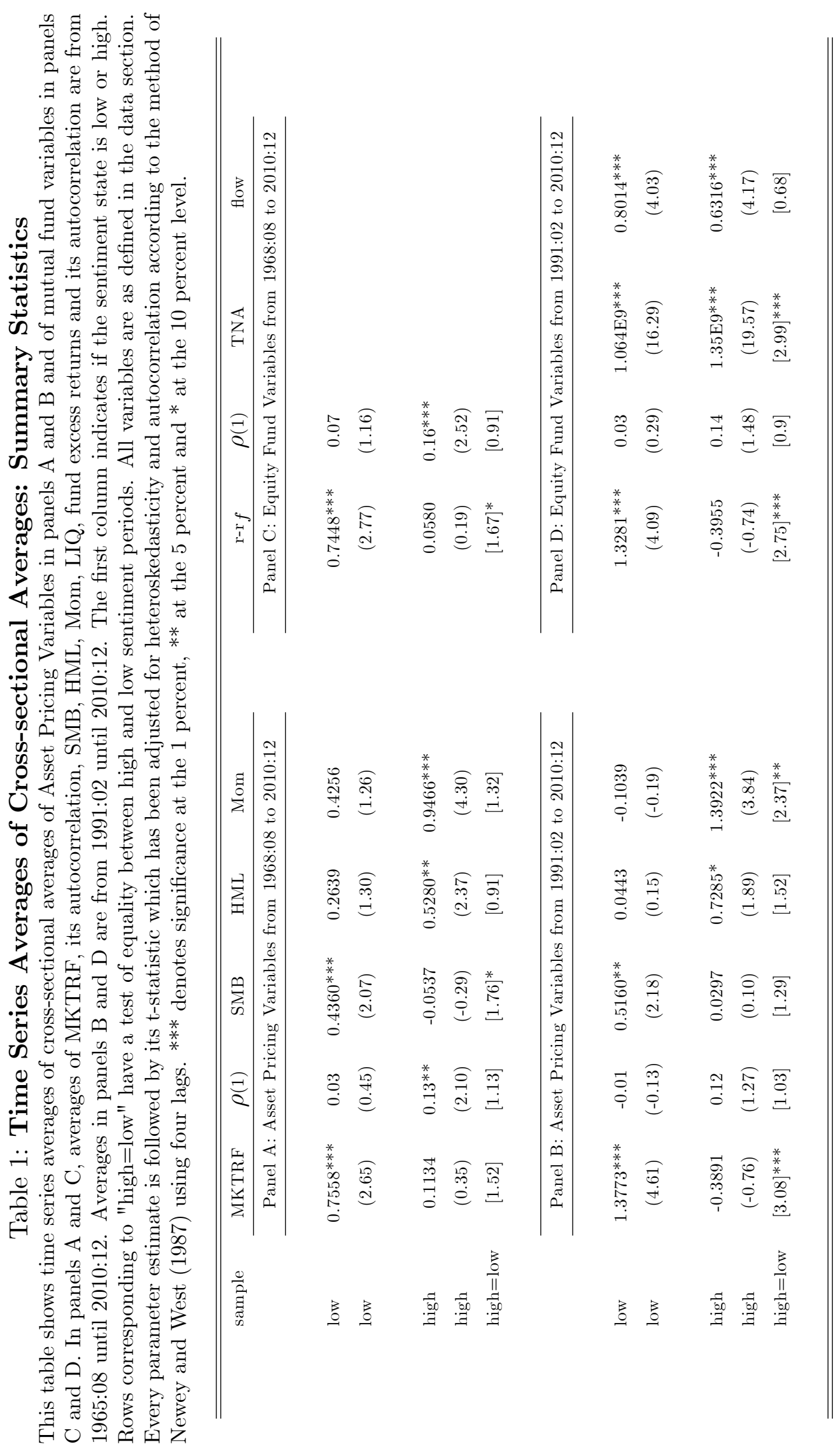




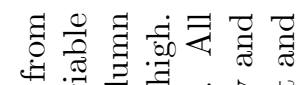

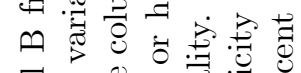

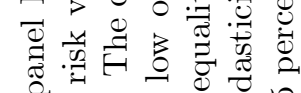

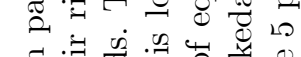

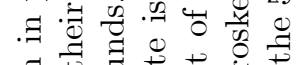
온

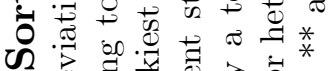

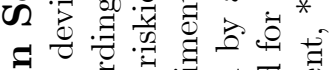

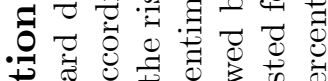

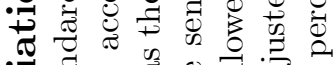
势

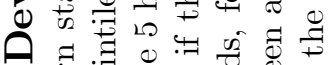
(1)

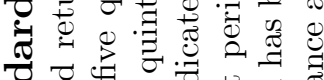

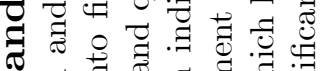

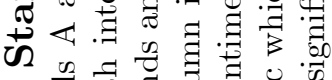

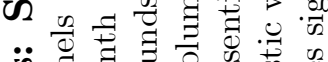

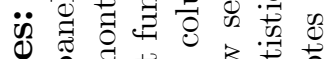

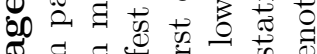

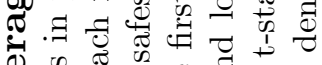

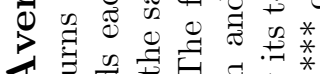

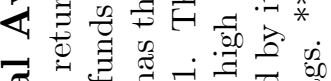

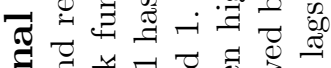

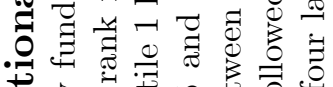
4

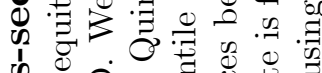

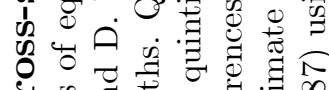

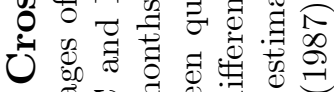

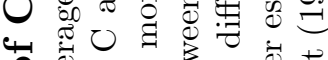

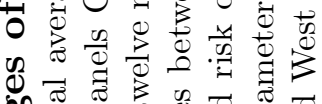
知商

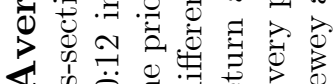

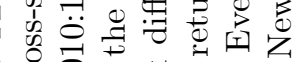

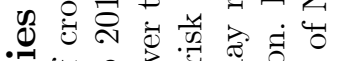

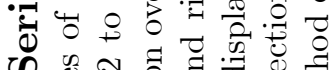
on

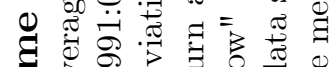

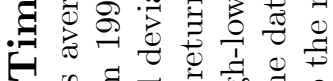

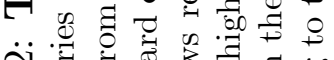

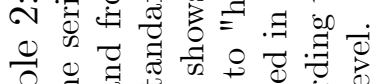

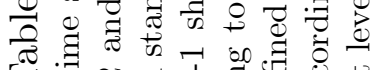

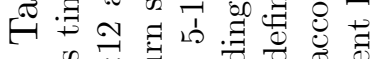

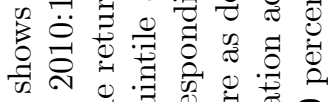

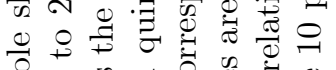

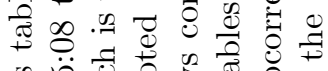

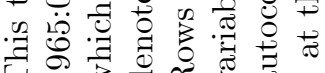

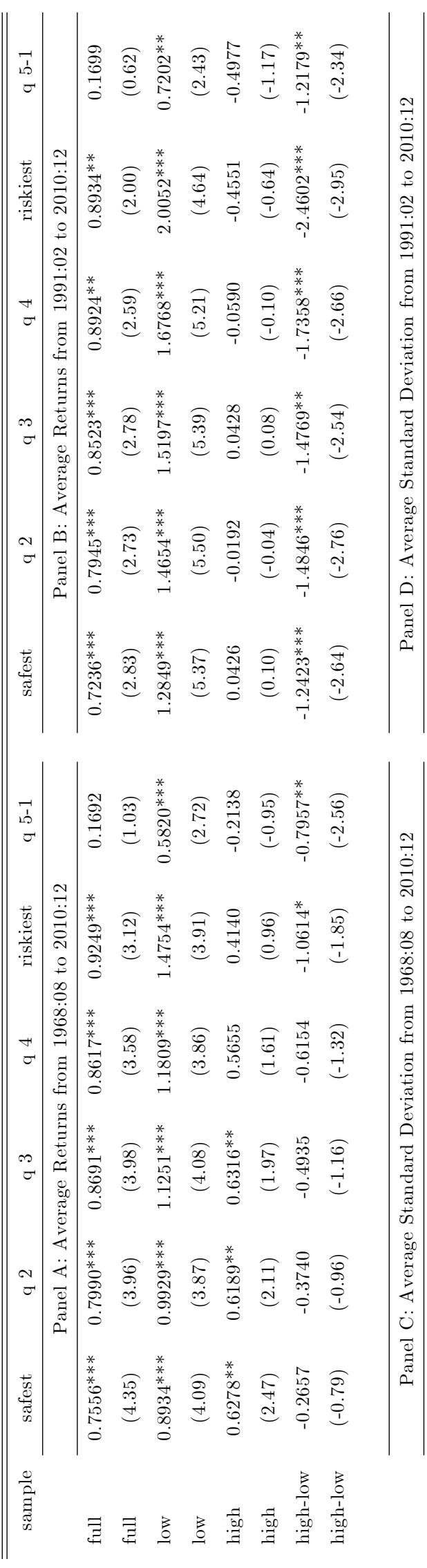

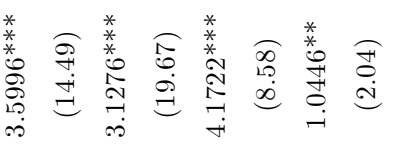

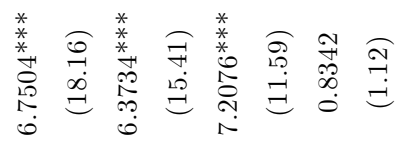

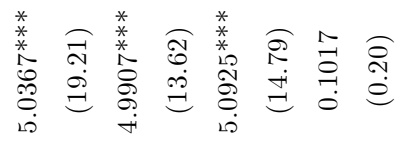

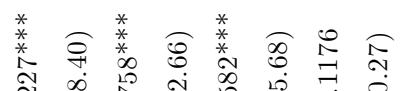

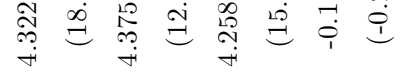

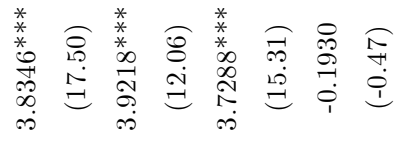

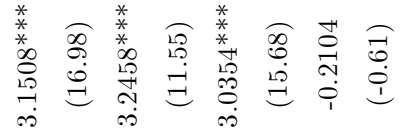

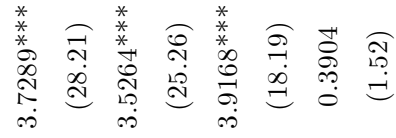

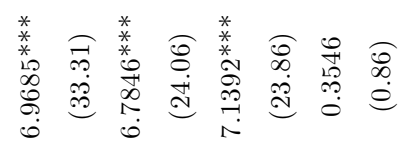

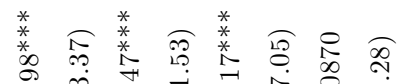

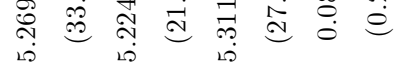

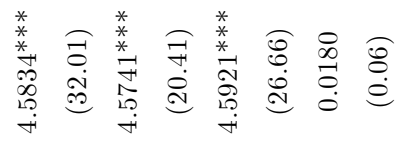

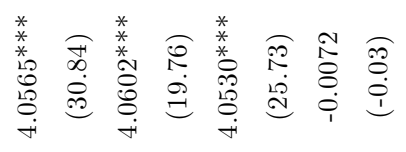

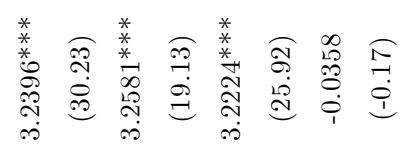

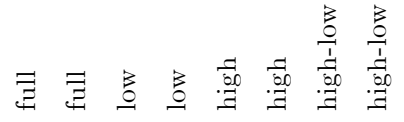




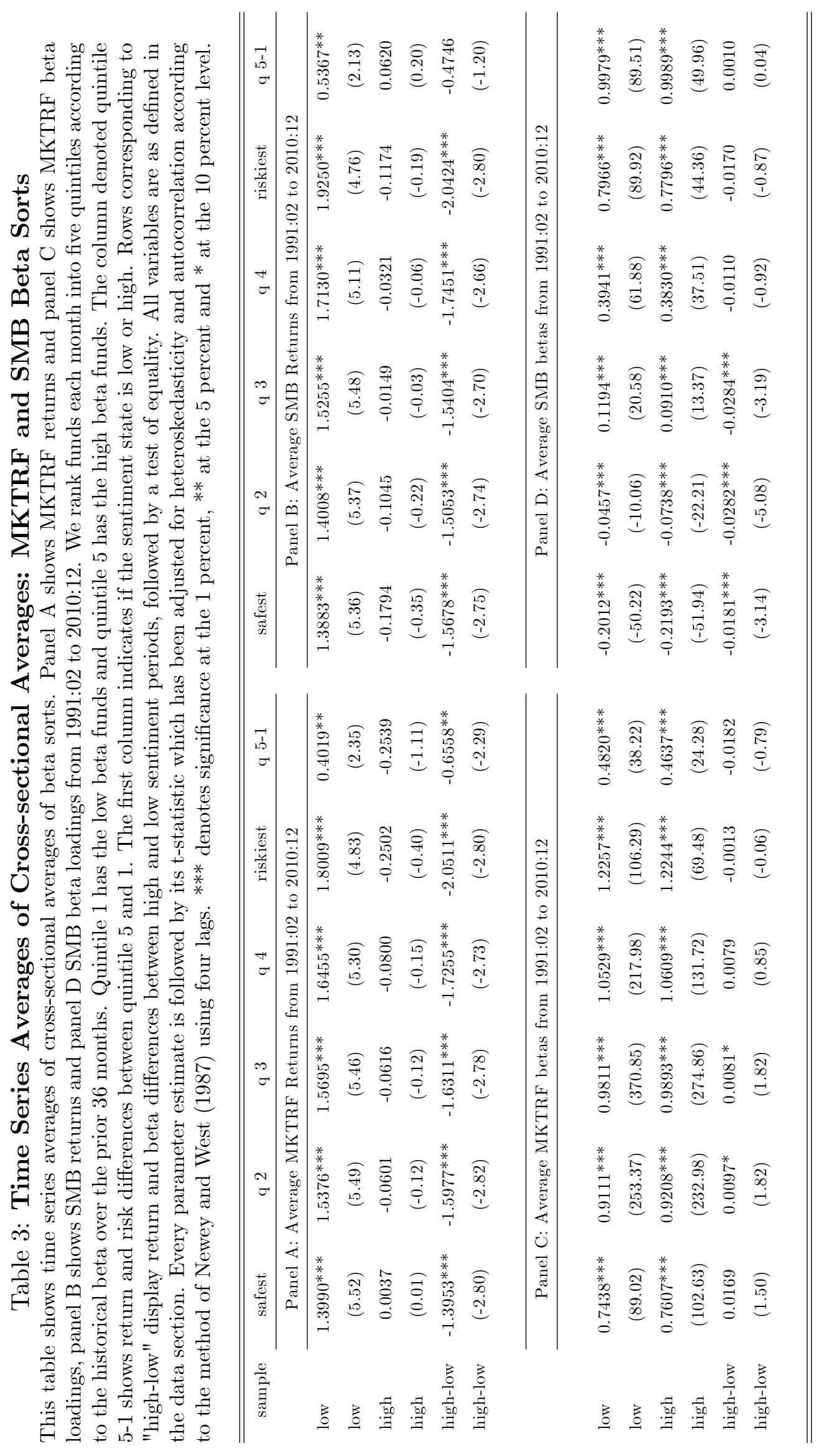


s. :

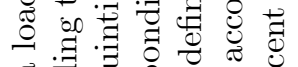

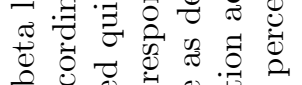

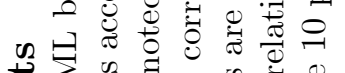

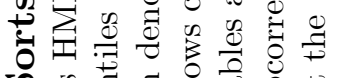

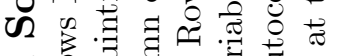
ซ అ๊

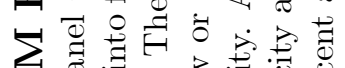

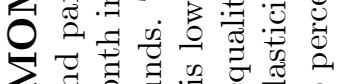
之 స

चै द्व

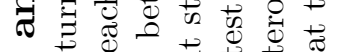

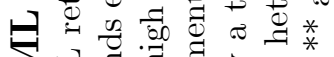

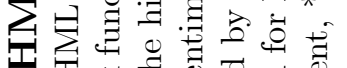
I

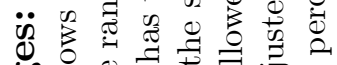
क人

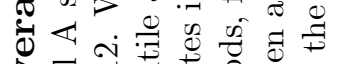

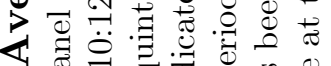
น すี่ 宅客

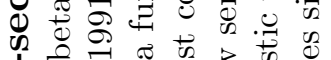

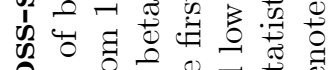

$0_{0}^{0} 0 \begin{gathered}0 \\ 0\end{gathered}$

U

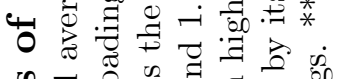

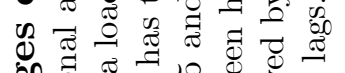

ช0.0

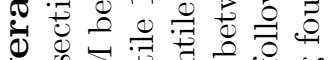

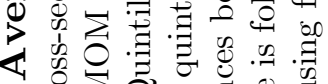

थ

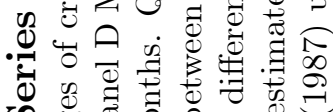

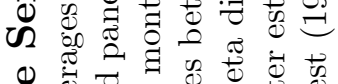

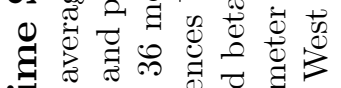

证.

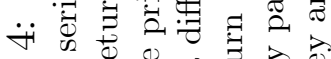

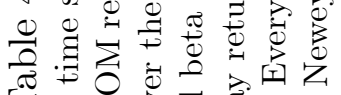
ए

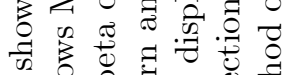
क 000

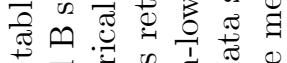

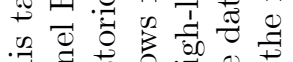

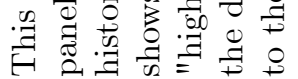
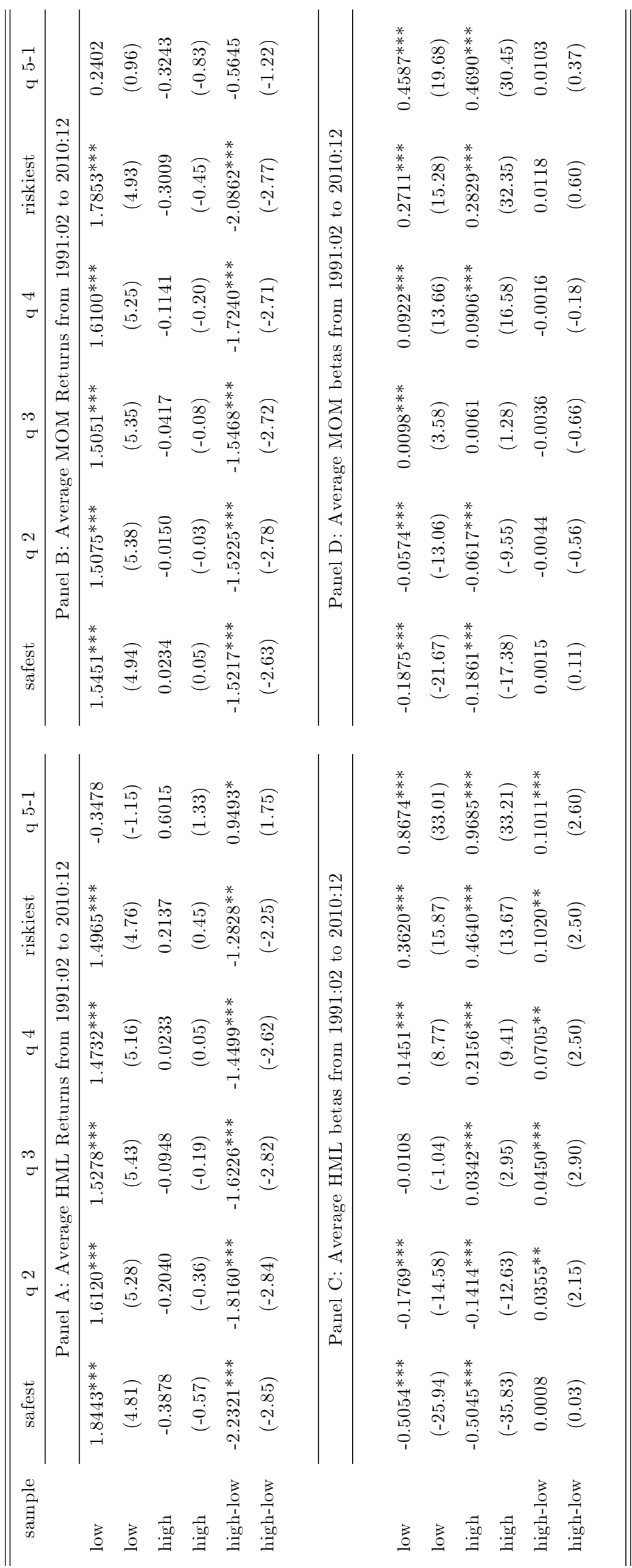


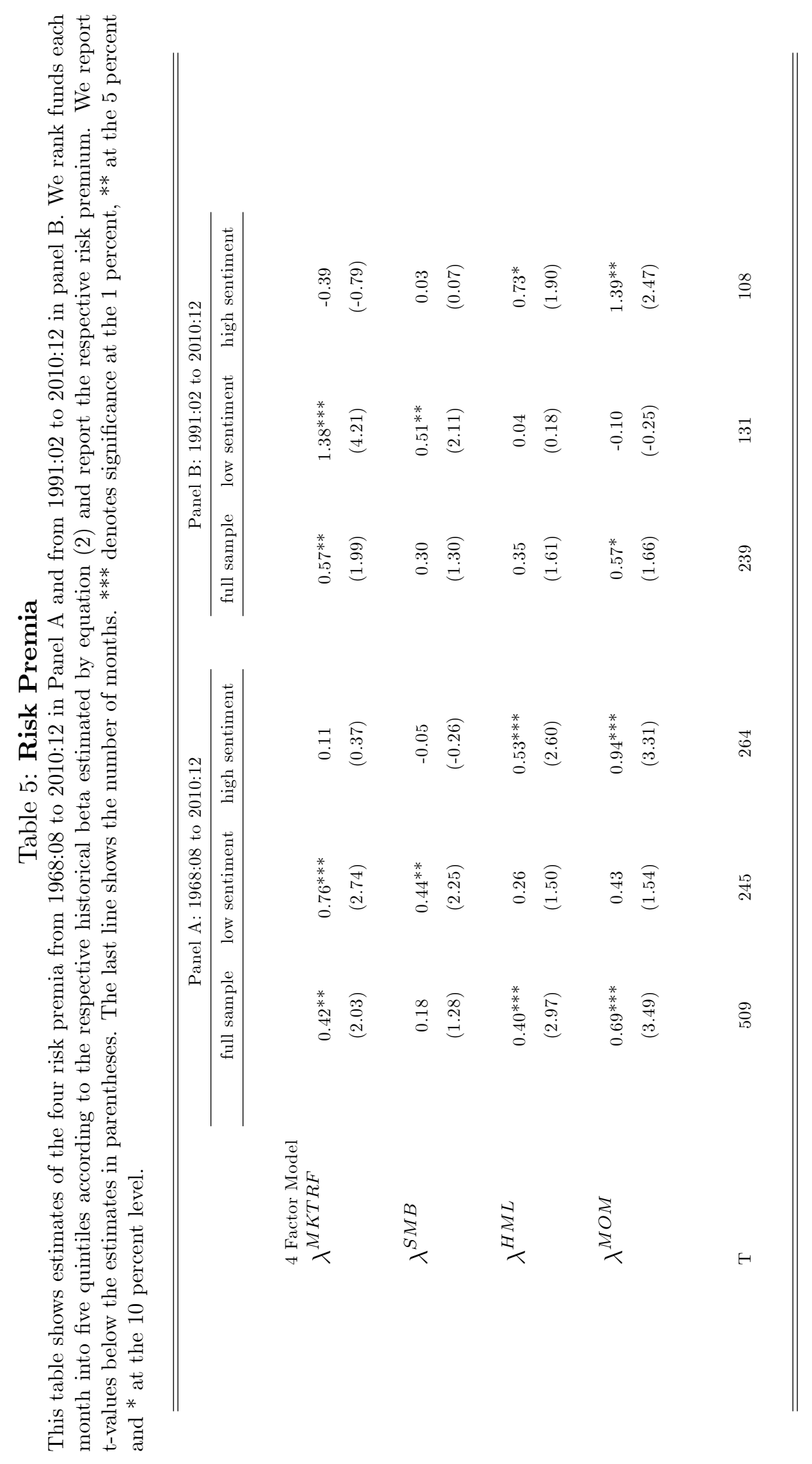




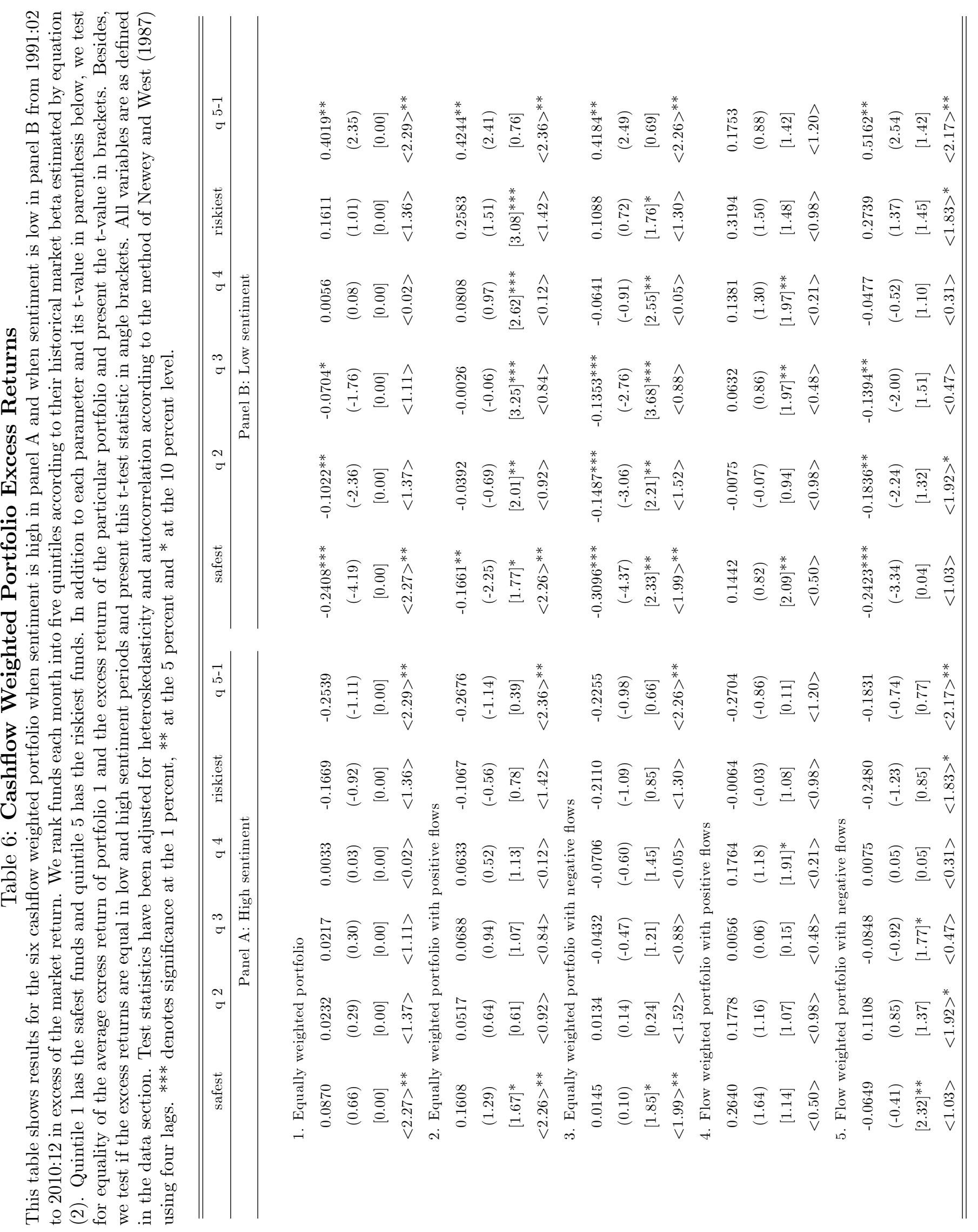




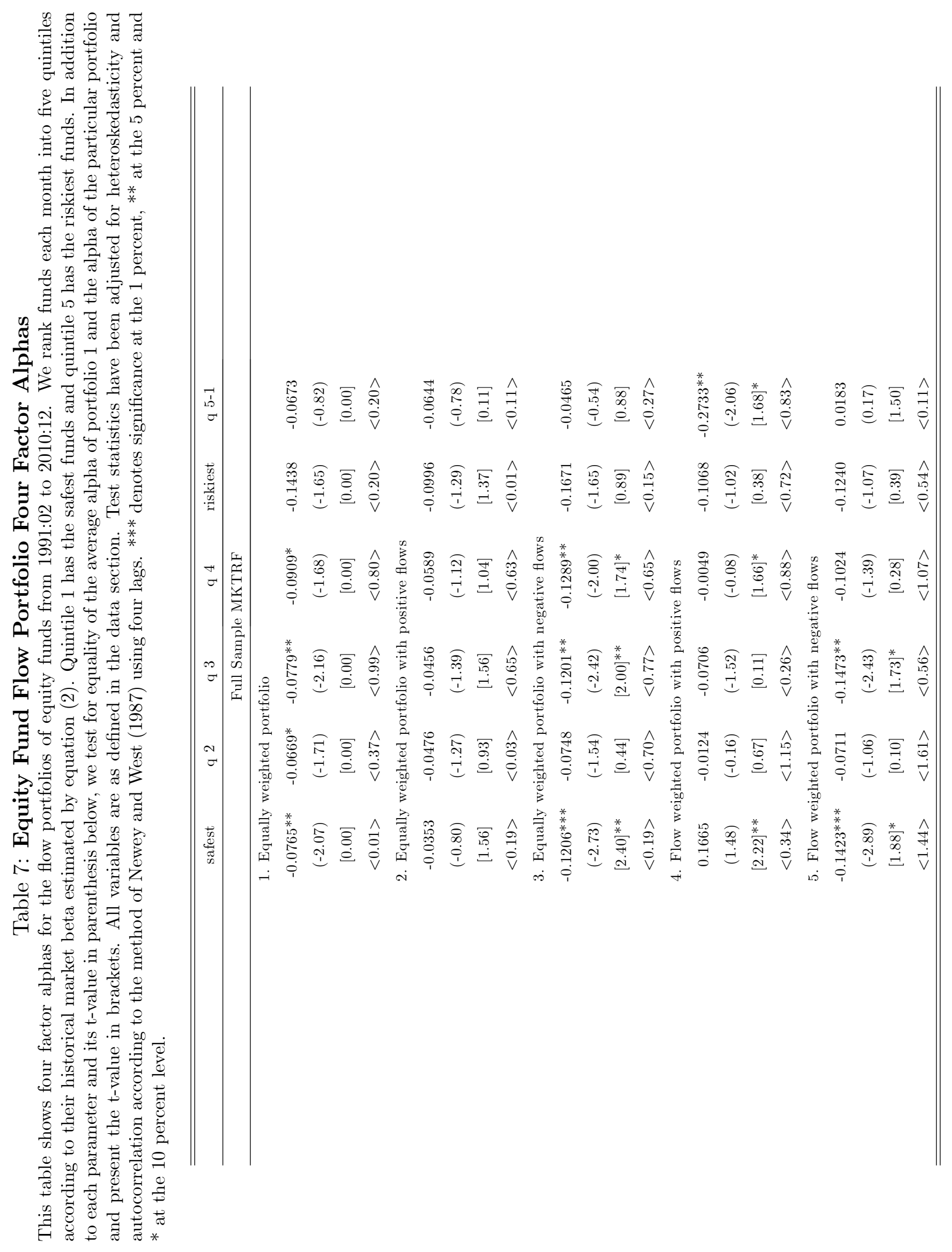




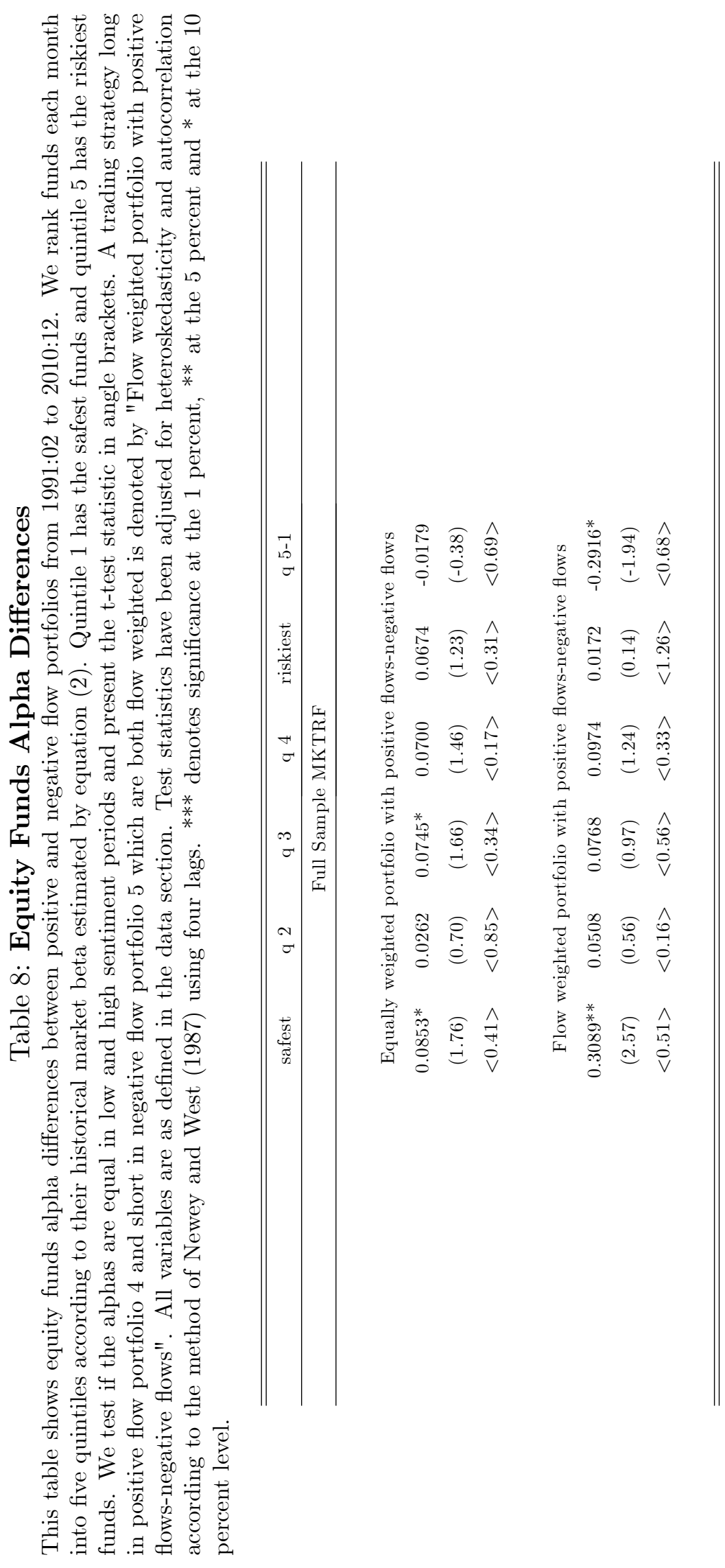




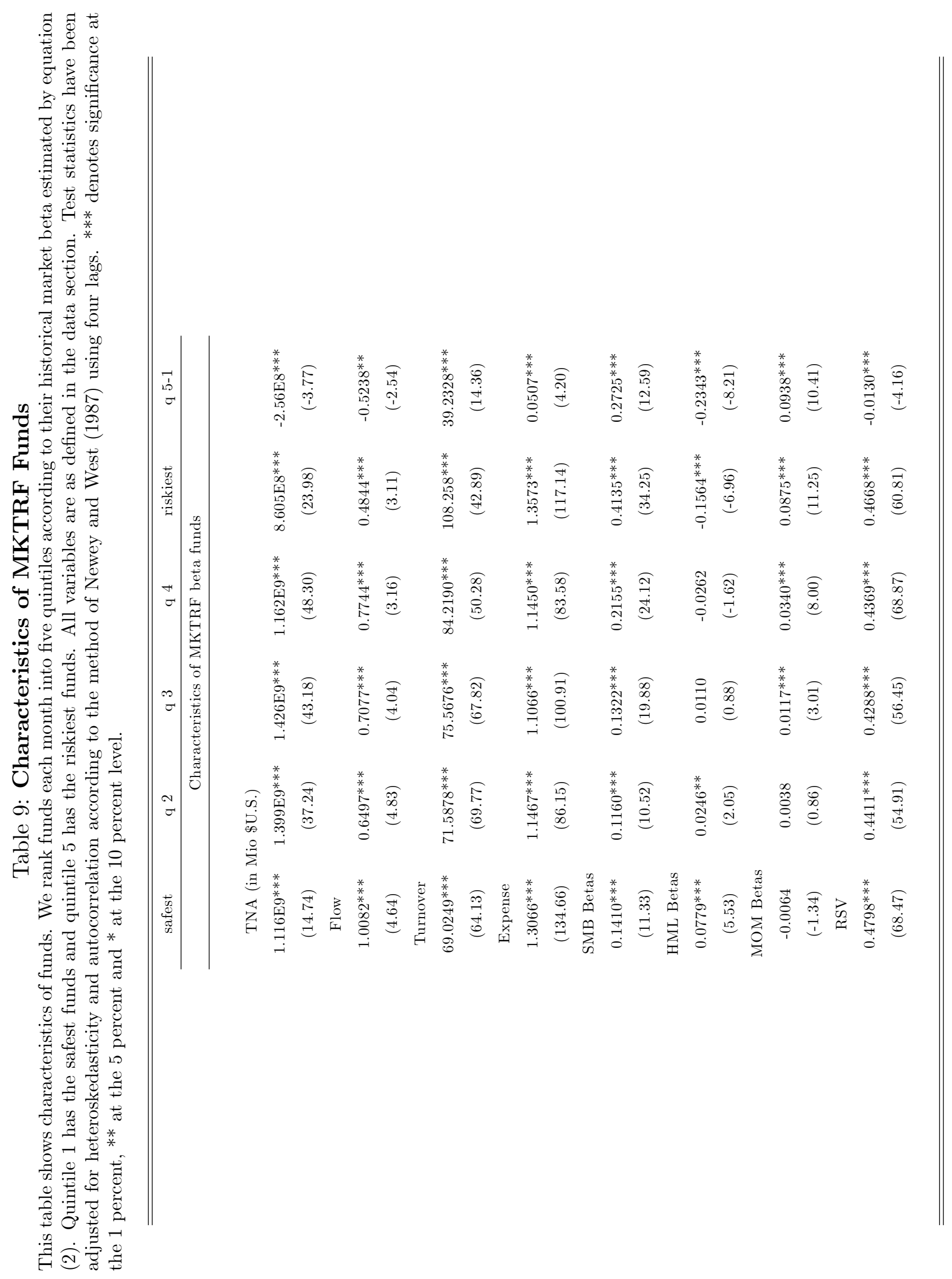




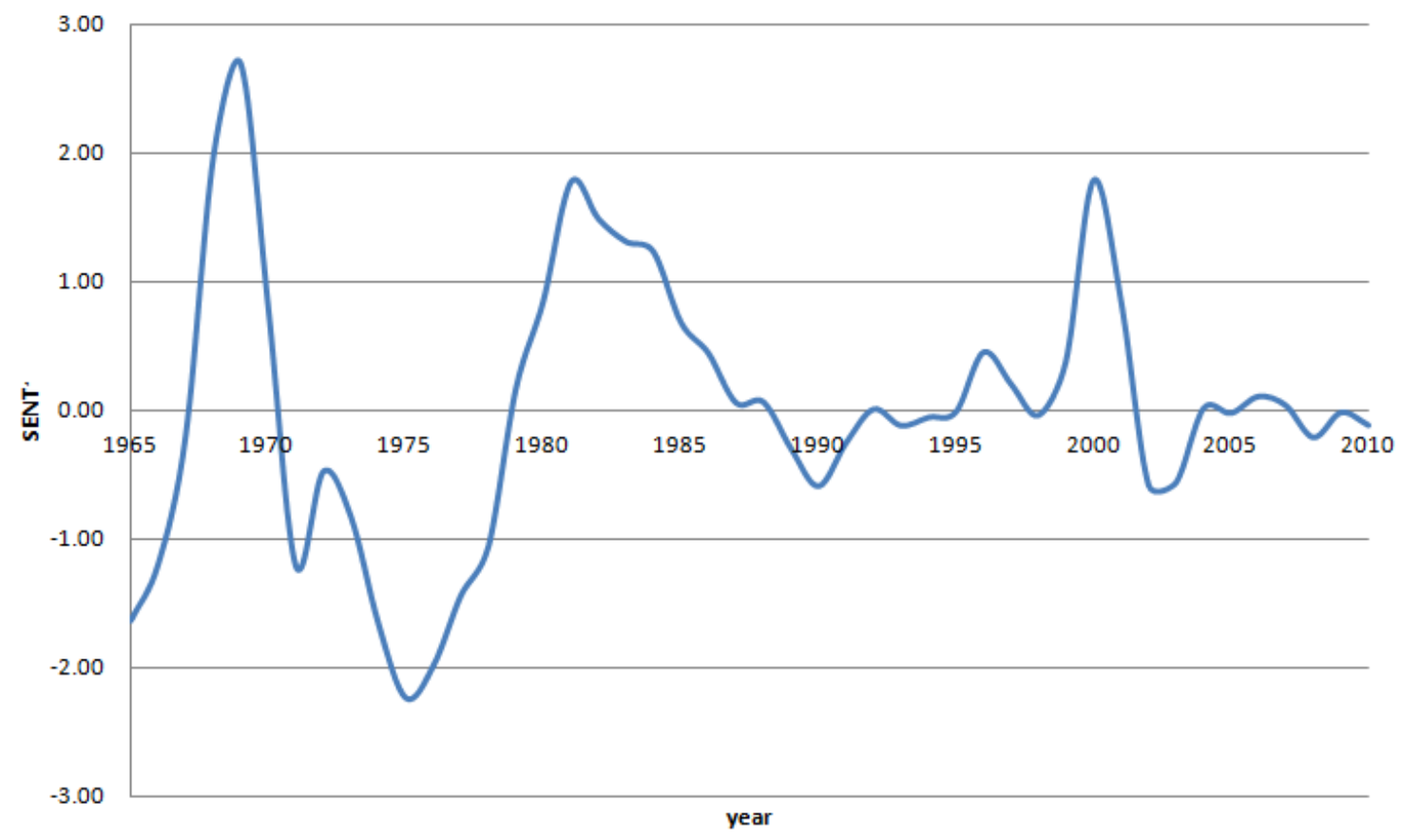

Figure 1: Sentiment. This figure shows the sentiment index $\mathrm{SENT}^{\perp}$ of Baker and Wurgler (2006) from 1965 to 2010. It is the first principal component of six sentiment proxies which have been orthogonalized with respect to six macroeconomic variables. In a first step, the average of lagged first-day returns on IPOs, the closed-end fund discount, lagged NYSE share turnover, lagged dividend pre-mium, the equity share in new issues and the number of IPOs are regressed on growth in industrial production, real growth in durable, nondurable, and services consumption, growth in employment, and a dummy for NBER recessions. In a second step, the residuals of each regression are used in principal component analysis. 


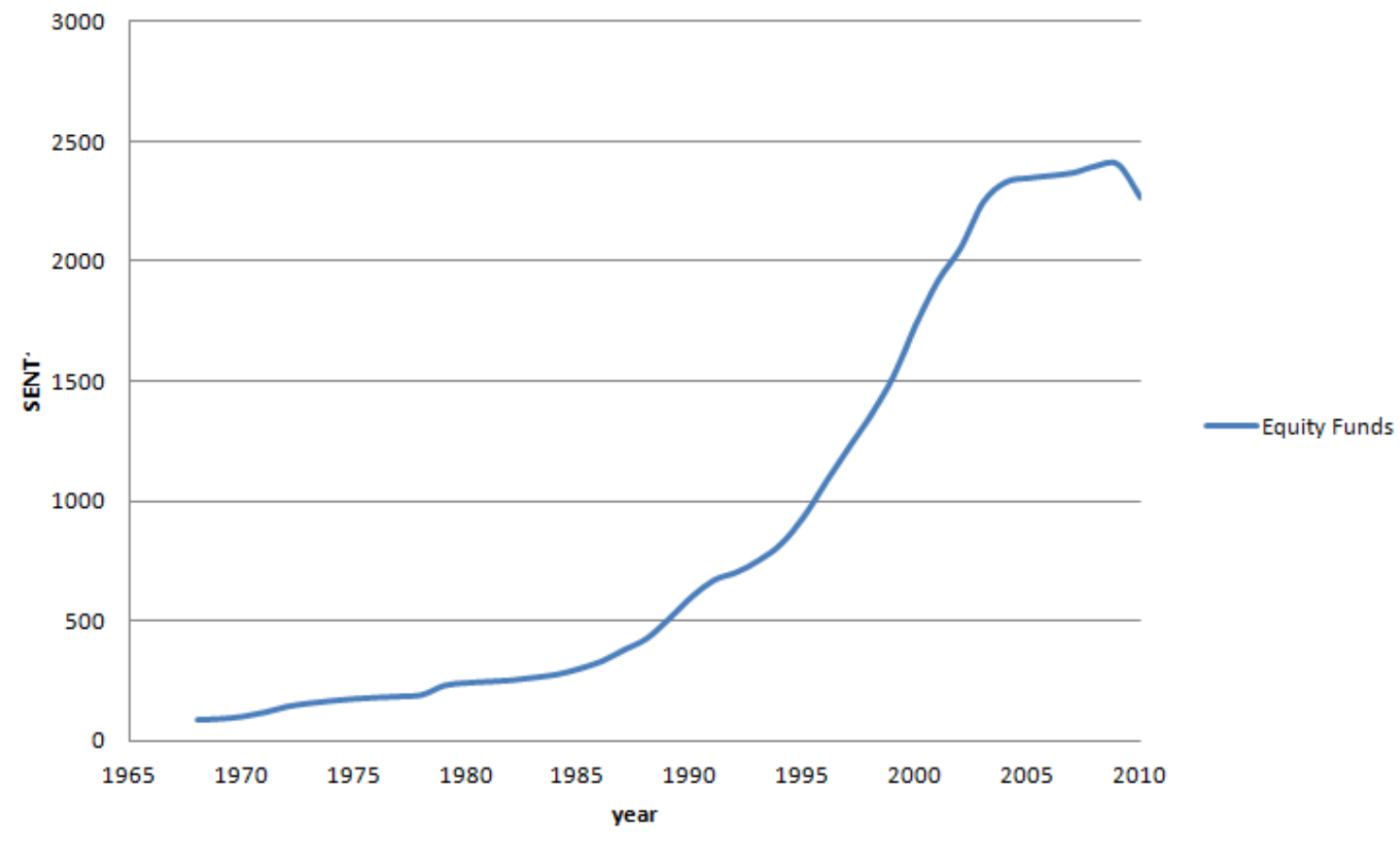

Figure 2:

Number of U.S. equity funds. This figure shows the yearly number of U.S. equity funds from 1968 to 2010 used in this study. Equity funds belong to the nine Morningstar categories Large-Cap Blend, Large-Cap Growth, Large-Cap,Value, Mid-Cap Blend, MidCap Growth, Mid-Cap Value, Small-Cap Blend, Small-Cap Growth, and Small-Cap Value.

\section{Appendix}

A short discussion of Morningstar's mutual fund data seems worthwhile as most studies use the U.S. Mutual Fund Database of the Center for Research in Security Prices (CRSP). This seems somewhat surprising as Morningstar is by no means worse than CRSP. Elton et al. (2001) show that CRSP suffers from omission bias as not all small funds are reporting, and that this effect is similar to survivorship bias. Besides, CRSP has upward biased returns when there are multiple distributions per month. The authors claim that both problems are severe for earlier observations, and that Morningstar is less affected. Besides, Morningstar was the main data provider of CRSP until 2008 (Elton et al. (2010)). 
Morningstar reports its data at the shareclass level. We transform returns and other variables from the shareclass to the portfolio level, i.e. we calculate the fund portfolio return (cash flow,expense ratio) from the corresponding shareclass returns (cash flow,expense ratio) weighted by their total net assets (TNA). The portfolio TNA are the sum of individual shareclass TNA. A rigorous check is applied to data to test for double entries. While return data has the fewest (only four) double entries, some other variables have more double entries, but still in modest proportion. Whenever an observation exists more than once, only one observation is kept if they are completely equal. In case of nonequal observations for the same point in time, all corresponding observations are deleted. It has become practice to exclude funds if they are too small (Chevalier (1997)). We delete funds with less than 1 Mio \$U.S. of TNA. Some studies delete funds with less than 10 Mio $\$$ U.S. of TNA, but we would lose $38 \%$ of all observations if we did so. When sorting on TNA, our lowest quintiles has an average monthly TNA of 24 Mio $\$$ U.S., which is very similar to that of the second quintile of Chen et al. (2004). Besides, latter authors show that even smaller funds do not drive results in their study. Since the sentiment index of Baker and Wurgler (2006) is available from 1965:8 onwards, our final sample starts at the same month and ends in 2010:12, which yields 545 months. As the rolling betas estimation needs at least 36 monthly observations, we delete all funds which have less than three years of return data. To ensure that outliers do not influence results, we winsorize all explanatory fund variables at the bottom and top 0.5 percent. As this does not change anything, we report the non-winsorized results. 